\title{
Is the robot necessary for enhanced recovery after minimally invasive surgery hepatectomy?
}

\author{
Richard S. Hoehn, Samer T. Tohme, David A. Geller \\ Department of Surgery, Liver Cancer Center, University of Pittsburgh Medical Center, Pittsburgh, PA, USA \\ Correspondence to: Dr. David A. Geller, MD, FACS. Director, UPMC Liver Cancer Center, Richard L. Simmons Professor of Surgery, University of \\ Pittsburgh School of Medicine, UPMC Montefiore, 7 South, 3459 Fifth Ave., Pittsburgh, PA 15213-2582, USA. Email: gellerda@upmc.edu. \\ Provenance and Peer Review: This article was commissioned by the Editorial Office, Hepatobiliary Surgery and Nutrition. The article did not undergo \\ external peer review. \\ Comment on: Melstrom LG, Warner SG, Woo Y, et al. Selecting incision-dominant cases for robotic liver resection: towards outpatient hepatectomy \\ with rapid recovery. HepatoBiliary Surg Nutr 2018;7:77-84.
}

Submitted Sep 25, 2019. Accepted for publication Oct 24, 2019.

doi: 10.21037/hbsn.2019.10.32

View this article at: http://dx.doi.org/10.21037/hbsn.2019.10.32

Minimally invasive surgery has become the standard of care for many operations, and laparoscopic liver resections have rapidly expanded over the past decade $(1,2)$. In 2014, an international panel of liver surgeons determined that laparoscopic minor hepatectomy is either superior or equivalent to traditional open surgery for when performed by trained experts, depending on the outcomes examined (3). In fact, laparoscopic liver surgery has been found to be costeffective compared to open surgery, owing to shorter length of stay, quicker recovery and less postoperative morbidity $(4,5)$. Indications and use of laparoscopic liver surgery have expanded in recent years from minor resections to major resection and living donor liver transplant, with safe and acceptable outcomes (3).

Similarly, surgeons have been investigating the robotic approach to liver resection, with mixed results. Robotic liver resection may be superior to the open approach, but studies have failed to show superiority over laparoscopic liver resection (6-8). Specifically, when compared to laparoscopy, robotic liver resection has been associated with increased blood loss, inflow occlusion time, conversion to open surgery, complications, and ICU use. In a 2:1 matched comparison of laparoscopic vs. robotic liver resection, Tsung et al. found robotic cases to require significantly longer operative time with no improvement in outcomes, and a trend towards higher blood loss and increased ICU utilization (9). Moreover, robotic liver resections are more expensive than laparoscopic hepatectomy when accounting for the substantial overhead and indirect costs of the robotic platform $(8,10)$.

Recent European guidelines state that the laparoscopic approach should be considered standard for lesions in the left lateral and anterior segments, but that lesions in the posterior and superior segments should be closely evaluated by experts to determine suitability for laparoscopic resection (11). The laparoscopic approach to these segments can be challenging, resulting in many cases being performed via an open approach. Some have used this rationale to support the robotic approach in these cases, suggesting that visualization and dexterity is superior to a standard laparoscopic approach (12). However, in a recent comparison of matched cohorts undergoing laparoscopic and robotic resection of lesions in the posterosuperior segments, outcomes were found to be equivalent between the two approaches, with robotic cases requiring longer inflow occlusion time (13).

Dr. Melstrom and colleagues recently published an analysis of 97 patients undergoing robotic liver resection, 87 of which were completed robotically (14). They demonstrate acceptable outcomes in their cohort, comparing their series to selected data from prior studies, and conclude that robotically-assisted hepatectomy is a superior approach, specifically for lesions in the posterosuperior segments. However, their conclusions are limited by the fact that only $33 \%$ of their cases were in the posterosuperior segments, and they do not provide information on the number or size of tumors in these cases. Moreover, there is no laparoscopic comparison group, so it is difficult to make conclusions about superiority. As previously discussed, laparoscopic hepatectomy has demonstrated equivalent or improved surgical outcomes when compared to robotic hepatectomy, with significantly lower cost.

It is certainly admirable that two-thirds of their patients were discharged by postoperative day 3 , and this is likely due to use of a minimally invasive approach along with enhanced recovery after surgery postoperative pathways, and less of an advantage of robotic over laparoscopic surgery. Likewise, 
many large laparoscopic liver resection series have shown average length of stay of 2-3 days in Western centers (15).

Their data suggest that healthy patients undergoing minor resections with low operative times and blood loss are most suited for such an enhanced recovery. The robotic hemihepatectomy cases in the current study were an elite group of patients: young, fit, and motivated with tumors in favorable anatomic locations. This may be the most important lesson learned from the study-identify patients who can benefit from minimally invasive liver surgery and accelerated postoperative management. In summary, the current study is a large series of robotic liver resections that adds to the growing number of single center reports demonstrating safety of robotic liver resection. Further comparative studies are warranted to determine if robotic liver resection provides advantages over a pure laparoscopic approach for tumors in difficult posterior-superior segments.

\section{Acknowledgments}

Funding: None.

\section{Footnote}

Conflicts of Interest: All authors have completed the ICMJE uniform disclosure form (available at https://hbsn. amegroups.com/article/view/10.21037/hbsn.2019.10.32/coif). The authors have no conflicts of interest to declare.

Ethical Statement: The authors are accountable for all aspects of the work in ensuring that questions related to the accuracy or integrity of any part of the work are appropriately investigated and resolved.

Open Access Statement: This is an Open Access article distributed in accordance with the Creative Commons Attribution-NonCommercial-NoDerivs 4.0 International License (CC BY-NC-ND 4.0), which permits the noncommercial replication and distribution of the article with the strict proviso that no changes or edits are made and the original work is properly cited (including links to both the formal publication through the relevant DOI and the license). See: https://creativecommons.org/licenses/by-nc-nd/4.0/.

\section{References}

1. Nguyen KT, Gamblin TC, Geller DA. World review of laparoscopic liver resection-2,804 patients. Ann Surg 2009;250:831-41.

2. Buell JF, Cherqui D, Geller DA, et al. The international position on laparoscopic liver surgery: The Louisville
Statement, 2008. Ann Surg 2009;250:825-30.

3. Wakabayashi G, Cherqui D, Geller DA, et al.

Recommendations for laparoscopic liver resection: a report from the second international consensus conference held in Morioka. Ann Surg 2015;261:619-29.

4. Vanounou T, Steel JL, Nguyen KT, et al. Comparing the clinical and economic impact of laparoscopic versus open liver resection. Ann Surg Oncol 2010;17:998-1009.

5. Cleary SP, Han HS, Yamamoto M, et al. The comparative costs of laparoscopic and open liver resection: a report for the 2nd International Consensus Conference on Laparoscopic Liver Resection. Surg Endosc 2016;30:4691-6.

6. Yan Y, Cai X, Geller DA. Laparoscopic Liver Resection: A Review of Current Status. J Laparoendosc Adv Surg Tech A 2017;27:481-6.

7. Troisi RI, Patriti A, Montalti R, et al. Robot assistance in liver surgery: a real advantage over a fully laparoscopic approach? Results of a comparative bi-institutional analysis. Int J Med Robot 2013;9:160-6.

8. Packiam V, Bartlett DL, Tohme S, et al. Minimally invasive liver resection: robotic versus laparoscopic left lateral sectionectomy. J Gastrointest Surg 2012;16:2233-8.

9. Tsung A, Geller DA, Sukato DC, et al. Robotic versus laparoscopic hepatectomy: a matched comparison. Ann Surg 2014;259:549-55.

10. Kim JK, Park JS, Han DH, et al. Robotic versus laparoscopic left lateral sectionectomy of liver. Surg Endosc 2016;30:4756-64.

11. Abu Hilal M, Aldrighetti L, Dagher I, et al. The Southampton Consensus Guidelines for Laparoscopic Liver Surgery: From Indication to Implementation. Ann Surg 2018;268:11-8.

12. Nota CL, Woo Y, Raoof M, et al. Robotic Versus Open Minor Liver Resections of the Posterosuperior Segments: A Multinational, Propensity Score-Matched Study. Ann Surg Oncol 2019;26:583-90.

13. Montalti R, Scuderi V, Patriti A, et al. Robotic versus laparoscopic resections of posterosuperior segments of the liver: a propensity score-matched comparison. Surg Endosc 2016;30:1004-13.

14. Melstrom LG, Warner SG, Woo Y, et al. Selecting incision-dominant cases for robotic liver resection: towards outpatient hepatectomy with rapid recovery. Hepatobiliary Surg Nutr 2018;7:77-84.

15. Nguyen KT, Marsh JW, Tsung A, et al. Comparative benefits of laparoscopic vs open hepatic resection: a critical appraisal. Arch Surg 2011;146:348-56.

Cite this article as: Hoehn RS, Tohme ST, Geller DA. Is the robot necessary for enhanced recovery after minimally invasive surgery hepatectomy? HepatoBiliary Surg Nutr 2020;9(2):219-220. doi: 10.21037/hbsn.2019.10.32 